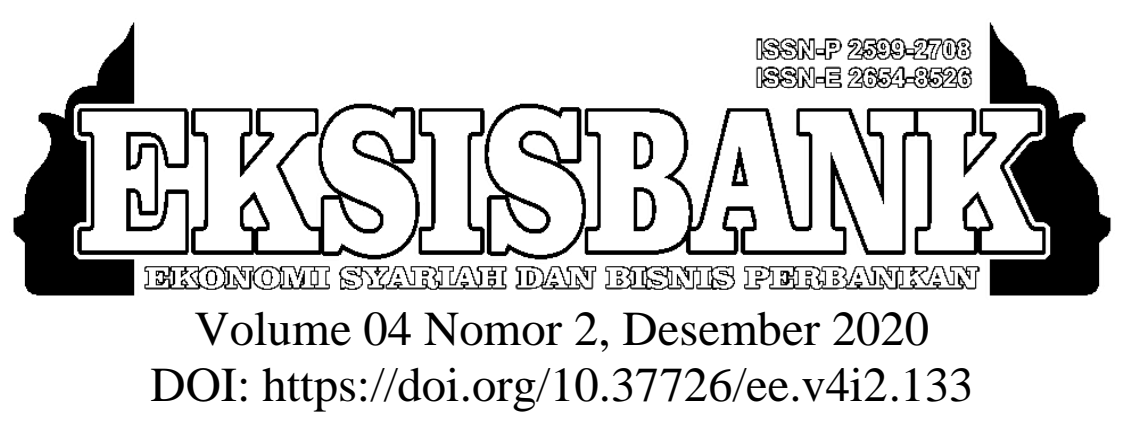

\title{
Kajian Ekonomi Syariah Dalam Pelaksanaan Asuransi Jaminan Kesehatan Pada Faskes Pertama Layanan BPJS Puskesmas Palasari Subang
}

\author{
Kiki Erika ${ }^{1}$, Rina Nurhayati ${ }^{2}$, Moch. Cahyo Sucipto ${ }^{3}$ \\ ${ }^{1}$ Sekolah Tinggi Agama Islam (STAI) Riyadhul Jannah Subang \\ ${ }^{2}$ Universitas Padjadjaran Bandung \\ ${ }^{3}$ Sekolah Tinggi Ilmu Ekonimi Syariah (STIES) Indonesia Purwakarta \\ $\frac{{ }^{1} \text { Kikierika442@gmail.com }}{{ }^{2} \text { inamaza@gmail.com }}$ \\ 3m.cahyosucipto@sties-purwakarta.ac.id
}

\begin{abstract}
ABSTRAK
Asuransi atau pertanggungan timbul karena kebutuhan manusia. Bahwa dalam kehidupan ini, manusia selalu dihadapkan kepada sesuatu yang tidak pasti, yang mungkin menguntungkan, tetapi mungkin pula sebaliknya. Iuran premi BPJS yang berbeda-beda menentukan kualitas pelayanan para penyedia layanan jasa kesehatan termasuk Faskes Pertama yang biasanya bertempat di Puskesmas Setempat. Layanan Faskes Pertama Puskesmas kadang berbeda layanannya dengan klinik padahal sama-sama bayar premi. Maka dari itu, Penelitian ini bertujuan untuk mengetahui pelaksanaan BPJS Kesehatan di Faskes pertama Puskesmas Palasari Ciater Subang; dan untuk menetahui pandangan Ekonomi Syariah terkait pelaksanaan BPJS Kesehatan di Faskes pertama Puskesmas Palasari Ciater Subang. Jenis penelitian ini adalah kualitatif dengan menggunakan metode deskriptif analisis. Sumber data yang digunakan meliputi data primer dan sekunder. Dari hasil pembahasan peneliti mendapatkan bahwa dalam pelaksanaannya seluruh warga Negara Indonesia diwajibkan untuk menjadi kepesertaan dari BPJS Kesehatan. Dalam pelaksanaannya di Puskesmas Palasari melayani dengan terbuka seluruh peserta BPJS Kesehatan yang penting mereka datang ke Puskesmas membawa kartu lalu di klik di tiketnya dan mereka merupakan anggota aktif. Pelaksaan jaminan kesehatan (BPJS Kesehatan) di Puskesmas Palasari dari segi pelayanan telah dilaksanakan sesuai dengan perundang-undangan, dan sesuai dengan Ekonomi Syariah.
\end{abstract}

Kata kunci- BPJS Kesehatan, Puskesmas, Ekonmi Syariah. 


\begin{abstract}
This research was conducted at the Palasari Ciater Health Center in Subang Regency. Puskesmas is one of the first-level health institutions in collaboration with BPJS. BPJS is a legal entity formed to organize social security programs, BPJS consists of BPJS Health and BPJS Employment. BPJS Health runs a health insurance program, while BPJS Employment operates a work accident insurance program, old age insurance, pension insurance and death insurance. This study aims to find out how the implementation of BPJS Health in the first Health Center in Palasari Ciater Subang Health Center and how the view of the Ekonmi Syariah related to the implementation of the first level BPJS Health in the first Health Center in Palasari Ciater Subang Health Center. This type of research is qualitative using descriptive analysis method. Data sources used include primary and secondary data. From the results of the discussion the researchers found that in its implementation all Indonesian citizens were required to become members of the Health BPJS. In its implementation at the Palasari Puskesmas openly serves all the important BPJS Health participants, they come to the Puskesmas carrying a card and then click on the ticket and they are active members. The implementation of health insurance (BPJS Kesehatan) at the Palasari Health Center in terms of service has been carried out in accordance with the law, and in accordance with the Sharia Economy.
\end{abstract}

Keywords - Health postdocs, economics, economy.

\section{PENDAhuluan}

Asuransi atau pertanggungan timbul karena kebutuhan manusia. Bahwa dalam kehidupan ini, manusia selalu dihadapkan kepada sesuatu yang tidak pasti, yang mungkin menguntungkan, tetapi mungkin pula sebaliknya. Manusia mengharapkan keamanan atas harta benda mereka, mengharapkan kesehatan dan kesejahteraan tidak kurang sesuatu apapun, namun manusia hanya dapat berusaha, tetapi Tuhan Yang Maha Kuasa yang menentukan segalanya. Oleh karena itu, setiap insan tanpa kecuali di dunia ini selalu menghadapi berbagai risiko yang merupakan sifat lemah manusia yang menunjukkan ketidakberdayaannya di bandingkan Sang Maha Pencipta. Kemungkinan menderita kerugian yang dimaksud dengan risiko (Ganie, 2013).

Pemerintah sebagai pengemban amanah rakyat bertanggung jawab penuh atas kemakmuran dan kesejahteraan rakyat. Untuk mewujudkan kemakmuran dan kesejahteraan, pemerintah menetapkan berbagai macam kebijakan dengan berbagai programnya. Jika suatu pemerintahan tidak mampu memenuhi kebutuhan dasar rakyatnya, mereka akan menaburkan benihbenih kehancuran melalui kegelisahan sosial dan ketidakstabilan politik (Capra, 1997). Diantara berbagai bentuk jaminan sosial, Jaminan Kesehatan merupakan sistem yang telah berdiri sejak lama dan sangat diperlukan oleh masyarakat. Jaminan Kesehatan merupakan pendorong pembangunan dan strategi penting dalam penanggulangan kemiskinan. Jaminan Kesehatan telah diakui sebagai satu strategi kebijakan sosial yang penting dalam menopang industri dan pertumbuhan ekonomi, bukan saja di negara-negara maju seperti Amerika Serikat dan Eropa Barat. Akses terhadap perawatan kesehatan merupakan faktor penting bagi pembangunan ekonomi. Ini menjelaskan mengapa proporsi besar anggaran dalam strategi penanggulangan kemiskinan diinvestasikan dalam bidang kesehatan. Kemiskinan

EKSISBANK (Ekonomi Syariah dan Bisnis Perbankan), Volume 4, Nomor 2, Desember 2020 


\section{Kiki Erika}

menghambat pembangunan ekonomi, menurunkan produktivitas, dan memicu instabilitas dan konflik social (Suharto, 2009).

Awal tahun 2014, tepat pada tanggal 1 Januari Pemerintah Indonesia melalui Kementerian Kesehatan mengoperasikan Program Jaminan Kesehatan Nasional (JKN). Program ini diselenggarakan oleh BPJS (Badan Penyelenggara Jaminan Sosial) Kesehatan yang merupakan lembaga yang dibentuk berdasarkan Undang-undang No. 24 Tahun 2011 tentang Badan Penyelenggara Jaminan Sosial yang diamanatkan dalam Undang-Undang No. 40 Tahun 2004 tentang Sistem Jaminan Sosial Nasional (SJSN). Jaminan Kesehatan Nasional (JKN) ini dijadikan sebagai upaya Pemerintah untuk mengayomi masyarakat kecil yang selama ini kesulitan untuk mendapatkan pelayanan kesehatan (Sukardi, 2016).

Menurut UU No. 24 Tahun 2011 Pasal 1 ayat (1) tentang Badan Penyelenggara Jaminan Sosial, bahwa Badan Penyelenggara Jaminan Sosial yang selanjutnya disingkat BPJS adalah badan hukum yang dibentuk untuk menyelenggarakan program jaminan sosial. Ruang lingkup BPJS dalam Undangundang ini tercantum pada Pasal 5 dan Pasal 6 , yang menyatakan bahwa BPJS terdiri dari BPJS Kesehatan dan BPJS Ketenagakerjaan. BPJS Kesehatan menyelenggarakan program jaminan kesehatan, sedangkan BPJS Ketenagakerjaan menyelenggarakan program Jaminan kecelakaan kerja, Jaminan hari tua, Jaminan pensiun dan Jaminan kematian (Sukardi, 2016).

Iuran premi BPJS yang berbeda-beda menentukan tingkat kualitas pelayanan para penyedia layanan jasa kesehatan. Pilihan Faskes pertama yang di harapakan oleh Peserta BPJS Kesehatan kadang tidak sesuai harapan, dikarenakan kapasitas Faskes pertama yang diharapkan sudah penuh. Pelayanan Faskes pertama di puskesmas kadang berbeda pelayanan yang ada di klinik, dan bahkan pelayanan BPJS Kesehatan di Puskesmas lebih tidak teratur dibandingkan
Kajian Ekonomi Syariah Dalam Pelaksanaan....

dengan klinik padahal para peserta BPJS Kesehatan sama-sama membayar premi. Maka dari itu peneliti merasa tertarik untuk mengambil judul penelitian Kajian Ekonomi Syariah Dalam Pelaksanaan Asuransi Jaminan Kesehata Pada Faskes Pertama Layanan BPJS Puskesmas Palasari Subang.

Penelitian ini bertujuan untuk: pertama untuk mengetahui pelaksanaaan BPJS Kesehatan di Faskes pertama Puskesmaas Palasari Ciater Subang, kedua untuk mengetahui pelaksanaaan BPJS Kesehatan dalam persfektip Ekonomi Syariah di Faskes pertama Puskesmaas Palasari Ciater Subang.

Ahli fiqh kontemporer Wahbah AzZuhaili mendefinisikan asuransi berdasarkan pembagiannya. Ia membagi asuransi dalam dua bentuk, yaitu at-ta'min at-ta'awuni dan at-ta'min bi qist sabit. At-ta'min at-ta'awuni atau asuransi tolong menolong adalah: kesepakatan sejumlah orang untuk membayar sejumlah uang sebagai ganti rugi ketika salah seorang diantara mereka mendapat kemudaratan (Dahlan, 2000).

Musthafa Ahmad Az-Zarqa memaknai asuransi sebagai suatu cara atau metode untuk memelihara manusia dalam menghindari risiko (ancaman) bahaya yang beragam yang akan terjadi dalam hidupnya, dalam perjalanan kegiatan hidupnya atau dalam aktivitas ekonominya. Ia berpendapat bahwa sistem asuransi adalah sistem ta'awun dan tadhamun yang bertujuan untuk menutupi kerugian peristiwa-peristiwa atau musibah-musibah oleh sekelompok tertanggung kepada orang yang tertimpa musibah tersebut. Penggantian tersebut berasal dari premi mereka (Sula, 2004b).

Beberapa dalil dalam Al-Quran dan AlHadits yang menjelaskan tentang Asuransi :

a. Firman Allah Q.S Al-Maidah ayat 2:

"Hai orang-orang yang beriman janganlah kamu melanggar syi'ar-syi'ar kesucian allah, dan jangan (melanggar kehormatan) bulan-

EKSISBANK (Ekonomi Syariah dan Bisnis Perbankan), Volume 4, Nomor 2, Desember 2020 


\section{Kiki Erika}

bulan haram, jangan mengganggu (hadyu) hewan-hewan qurban, dan (qalaid) hewanhewan qurban yang diberi tanda, dan jangan pula mengganggu orang-orang yang mengunjungi baithulharam; mereka mencari karunia dan dan keridhaan tuhannya. Tetapi tetaplah kamu telah menyelesaikan ihram, maka bolehlah kamu berburu. Jangan sampai kebencianmu kepada suatu kaum Karena mereka menghalang-halangimu dari masjidil haram mendorongmu berbuat melampaui batas kepada mereka. Dan tolongmenolonglah kamu dalam (mengerjakan) kebajikan dan takwa, dan jangan tolongmenolong dalam berbuat dosa dan pelanggaran. Dan bertakwalah kamu kepada Allah, sesungguhnya Allah amat berat siksaNya" (RI, 2009).

b. Al-Hadist

Hadits tentang menolong orang lemah

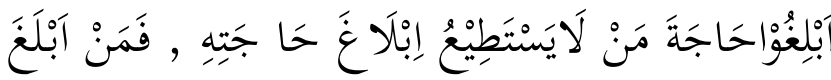

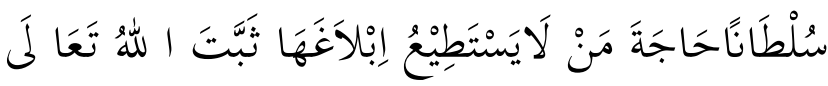

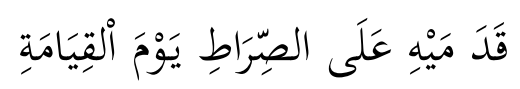

"Sampaikanlah keperluan orang yang tidak mampu untuk menyampaikan keperluannya kepada sultan. Barang siapa yang (menolong) menyampaikan keperluan (orang tersebut) kepada sultan, kelak di hari kiamat Allah SWT akan menetapkan kedua telapak kakinya diatas shirathal mustaqim”. (HR. At-Thabrani dari Abu Darda).

Prinsip dasar yang ada dalam asuransi syari'ah adalah sebagai berikut (Ali, 2004): Prinsip tauhid adalah dasar utama dari setiap bentuk bangunan yang ada dalam syari'ah Islam. Setiap bangunan dan aktivitas kehidupan manusia harus didasarkan pada nilai-nilai tauhid, Prinsip kedua dalam berasuransi adalah terpenuhinya nilainilai keadilan antara pihak-pihak yang terikat dengan akad asuransi. Keadilan dalam hal ini dipahami sebagai upaya dalam menempatkan
Kajian Ekonomi Syariah Dalam Pelaksanaan....

hak dan kewajiban di antara nasabah (anggota) dan perusahaan asuransi, prinsip dasar yang lain dalam melaksanakan kegiatan berasuransi harus didasari dengan semangat tolong-menolong antara anggota (nasabah), Prinsip kerja sama merupakan prinsip universal yang selalu ada dalam literatur ekonomi islam. Manusia sebagai makhluk yang mendapat mandat dari khaliqNya untuk mewujudkan perdamaian dan kemakmuran di muka bumi mempunyai dua wajah yang tidak dapat dipisahkan satu sama lainnya, yaitu sebagai mahluk individu dan sebagai mahluk sosial, Prinsip amanah dalam organisasi perusahaan dapat terwujud dalam nilai-nilai akuntabilitas (pertanggungjawaban) perusahaan melalui penyajian laporan keuangan tiap periode, Prinsip kerelaan dalam ekonomika islami yaitu keharusan untuk bersikap rela dan ridha dalam setiap melakukan akad (transaksi), dan tidak ada paksaan antara pihak-pihak bertransaksi atas dasar kerelaan bukan paksaan, Transaksi seorang muslim tidak dibenarkan untuk memperkaya diri dengan cara yang tidak dibenarkan atau secara bathil, Prinsip larangan judi dalam sistem asuransi syariah untuk menghindari satu pihak yang untung dan pihak yang lain rugi, Gharar dalam pandangan ekonomi Islam terjadi apabila dalam suatu kesepakatan/perikatan antara pihak-pihak yang terikat terjadi ketidakpastian dalam jumlah profit (keuntungan) maupun modal yang dibayarkan (premi).

Jenis-jenis asuransi syariah: Pertama Takaful Keluarga (Asuransi Jiwa) adalah bentuk asuransi syariah yang memberikan perlindungan dalam menghadapi musibah kematian dan kecelakaan atas diri peserta asuransi takaful. Produk asuransi takaful keluarga meliputi (G. Dewi, 2004): Takaful berencana, Takaful pembiayaan, Takaful pendidikan, Takaful dana haji, Takaful berjangka, Takaful kecelakaan siswa, Takaful kecelakaan diri, Takaful khairat keluarga. Kedua Takaful Umum (asuransi

EKSISBANK (Ekonomi Syariah dan Bisnis Perbankan), Volume 4, Nomor 2, Desember 2020 


\section{Kiki Erika}

Kerugian) adalah bentuk asuransi syariah yang memberikan perlindungan finansial dalam menghadapi bencana atau kecelakaan atas harta benda milik peserta takaful. Produk-produk Asuransi Takaful umum adalah (G. Dewi, 2004): Takaful kebakaran, Takaful kendaran bermotor, Takaful pengangkutan.

\section{TINJAUAN PUSTAKA}

Penelitian tentang Kajian Ekonomi Syariah Dalam Pelaksanaan Asuransi Jaminan Kesehata Pada Faskes Pertama Layanan BPJS sudah banyak dilakukan oleh peneliti sebelumnya, tapi tentu saja mempunyai perbedaan-perbedaan antara penelitian ini dengan penelitian sebelumnya. Berikut adalah penelitian sebelumnya yang meneliti tentang Kajian Ekonomi Syariah Dalam Pelaksanaan Asuransi Jaminan Kesehata Pada Faskes Pertama Layanan BPJS Puskesmas Palasari Subang;

1. Perspektif Hukum Islam Terhadap Iuran BPJS Kesehatan (Analisis Atas Bab V Pasal 19 Ayat 3 Undang-Undang Nomor 24 Tahun 2011 Tentang Badan Penyelenggara Jaminan Sosial) (Nurmatias et al., 2017)

Hasil penelitian menunjukkan bahwa Negara bertanggung jawab penuh terhadap kesehatan rakyat, karena kesehatan rakyat merupakan kebutuhan pokok rakyat yang harus dipenuhi, negara harus menyediakan obat-obatan, menyediakan sumberdaya dalam pelayanan kesehatan, dan negara harus mengatur sedemikian rupa jangan sampai mempersulit akses kesehatan bagi masyarakat, karena imam (khalifah) yang menjadi pemimpin manusia laksana pengembala, hanya dialah yang bertanggung jawab terhadap urusan rakyatnya. Perspektif hukum Islam terhadap Badan Penyelenggara Jaminan Sosial (BPJS) Kesehatan di Indonesia yang berprinsip Asuransi sosial menurut penulis adalah BPJS yang diterapkan di indonesia dengan kondisi saat ini belum tepat karena dapat menimbulkan
Kajian Ekonomi Syariah Dalam Pelaksanaan....

kemudharatan, yaitu iuran/premi bulanan yang akan disetorkan kepada pihak BPJS masih terlalu tinggi dan adanya penetapan sanksi bagi yang tidak membayar iuran, Program BPJS kesehatan masih mengandung unsur ketidak adilan dalam konsep At Takaful Al Ijtma', dengan iuran yang diberikan terdapat pemisahan masyarakat miskin, menengah dan orang kaya, terlebih dalam pelayanan, BPJS kesehatan dalam praktiknya masih mengandung unsur maishir, gharar, dan rhiba, sehingga menurut penulis hukumnya jatuh jadi syubahat. Perbedaannya dengan penelitian sekarang adalah peneliti tidak menganalisis terhadap Undang-undang tentang penyelenggara Jaminan Sosial. dan penelitian hanya ruang lingkup Puskesmas Palasari Subang saja tidak secara Global/ Nasional.

2. Social Accounting; Tendensi Kemaslahatan Publik dibalik Kenaikan Tarif BPJS Kesehatan di Indonesia (Majid \& Saputra, 2020)

Hasil penelitian menunjukkan bahwa kenaikan tarif BPJS memberikan dua dampak terhadap masyarakat sesuai dengan tinjauan akuntansi sosial, yakni cost and benefit. Kenaikan tarif BPJS Kesehatan akan menurunkan partisipasi masyarakat terkait dengan pembayaran iuran yang disebabkan oleh kurangnya manfaat sosial yang mereka terima dari adanya program BPJS Kesehatan. Akibatnya, masyarakat secara legitimasi akan cenderung untuk tidak percaya lagi kepada pemerintah karena kebijakan terkait kenaikan tarif BPJS Kesehatan dianggap tidak sesuai dengan kebutuhan dan keinginan masyarakat. Kajian mendalam perlu dilakukan oleh pemerintah terkait kebijakan ini agar tendensi positif terkait kemaslahatan masyarakat dalam bidang kesehatan dapat dipenuhi secara maksimal. Perbedaan dengan penelitian Kajian Ekonomi Syariah Dalam Pelaksanaan Asuransi Jaminan Kesehatan Pada Faskes Pertama Layanan BPJS Puskesmas Palasari Subang, penelitian ini

EKSISBANK (Ekonomi Syariah dan Bisnis Perbankan), Volume 4, Nomor 2, Desember 2020 


\section{Kiki Erika}

hanya terfokus di Puskesmas Palasari subang saja bukan secara nasional. Metode penelitian yang digunakan adalah kualitatif dengan pendekatan deskriptif bukan interpretif.

\section{Sistem Kapitasi BPJS Kesehatan Dalam Tinjauan Syariah (Ananta, 2017)}

Metode penelitian yang digunakan dalam membedah polemik syariah pada kasus ini dengan melakukan studi kritis terhadap penerapan sistem kapitasi pada BPJS Kesehatan. Melalui pola pendekatan interaktif yang menyesuaikan informasi pelaku atas fakta-fakta dilapangan dengan merujuk kepada literatur kajian fikih mu'amalah islam, peraturan pemerintah, ketentuan dan modus transaksi yang dilakukan BPJS Kesehatan serta wawancara dan observasi langsung. Penerapan kapitasi di BPJS Kesehatan terindikasi mengandung unsur gharar dengan muatan besar yang bermasalah secara syariah, dengan pengungkapan fakta ini semoga bermanfaat menjadi bahan kajian mendalam bagi pemerintah selaku regulator dalam memperbaiki sistem yang telah berjalan dan masyarakat muslim merasakan ketenangan secara spritual dalam memanfaatkan layanan BPJS kesehatan ini. Perbedaan dengan penelitian Kajian Ekonomi Syariah Dalam Pelaksanaan Asuransi Jaminan Kesehatan Pada Faskes Pertama Layanan BPJS Puskesmas Palasari Subang, penelitian ini terfokus pada layanan Puskesmas bukan pada kapitasi BPJS. Penelitian ini juga hanya terfokus di Puskesmas Palasari subang saja bukan secara nasional. Metode penelitian yang digunakan adalah kualitatif dengan pendekatan deskriptif.

\section{BPJS Kesehatan dalam Perspektif} Ekonomi Syariah (Itang, 2015)

Artikel ini memberikan jawaban terhadap pernyataan MUI tentang BPJS tidak sesuai dengan prinsip ekonomi syariah. Pertama, solusi agar tidak terjadi gharâr, di mana
Kajian Ekonomi Syariah Dalam Pelaksanaan....

peserta bayar premi bulanan namun tidak jelas berapa jumlah yang akan diterima. Kedua, solusi agar tidak terjadi unsur judi, di mana perhitungan keuangan bisa jadi untung atau bisa jadi rugi. Ketiga, solusi tentang riba, ketika klaim yang diterima peserta BPJS lebih besar dari premi yang dibayarkan. Hal tersebut mengandung unsur riba dan termasuk kategori riba fadhl. Sedangkan ketika terjadi keterlambatan peserta dalam membayar premi, BPJS menetapkan denda yang juga termasuk riba nasi'ah. Perbedaan dengan penelitian Kajian Ekonomi Syariah Dalam Pelaksanaan Asuransi Jaminan Kesehatan Pada Faskes Pertama Layanan BPJS Puskesmas Palasari Subang, penelitian ini terfokus pada layanan Puskesmas bukan pada kapitasi BPJS. penelitian ini hanya terfokus di Puskesmas Palasari subang saja bukan secara nasional. Metode penelitian yang digunakan adalah kualitatif dengan pendekatan deskriptif.

\section{METODOLOGI PENELITIAN}

Metode yang digunakan dalam penelitian ini adalah metode kualitatif. Dengan menggunakan metode ini, peneliti dapat memaparkan (mendeskripsikan) maupun memberikan gambaran suatu satuan analisis secara utuh yang terintegritas. Dalam metode ini satuan analisis yang dimaksud berupa satuan penellitian yang dilakukan secara intensif, terinci dan mendalam terhadap suatu daerah (Arikunto, 2002).

Dalam hal ini penulis akan megumpulkan, mengelola, mengklarifikasi, menganalisis data dan melaporkan hasil penelitian objektif sesuai dengan hasil penelitian lapangan berupa observasi dan wawancara dengan informan atau pihak pihak yang terlibat dalam penelitian ini diantaranya pihak Puskesmas Palasari, petugas BPJS dan Pasien Peserta BPJS Kesehatan, serta Pihak MUI Kab. Subang. juga referensi dari berbagai sumber bacaan.

\section{PEMBAHASAN}

EKSISBANK (Ekonomi Syariah dan Bisnis Perbankan), Volume 4, Nomor 2, Desember 2020 
Kiki Erika

A.Mekanisme Pelaksanaan Jaminan Asuransi Kesehatan Pada Faskes Pertama Layanan BPJS Puskesmas Palasari Kabupaten Subang

BPJS merupakan lembaga baru yang dibentuk untuk menyelenggarakan program jaminan sosial di Indonesia yang bersifat nirlaba berdasarkan Undang-Undang Nomor 40 Tahun 2004 tentang SJSN. Berdasarkan Undang-undang Nomor 24 Tahun 2011, BPJS akan menggantikan sejumlah lembaga jaminan sosial yang ada di Indonesia yaitu lembaga asuransi jaminan kesehatan PT Askes dan lembaga jaminan sosial ketenagakerjaan PT Jamsostek. Transformasi PT Askes dan PT Jamsostek menjadi BPJS akan dilakukan secara bertahap. Pada awal 2014, PT Askes akan menjadi BPJS Kesehatan, selanjutnya pada 2015 PT Jamsostek yang akan menjadi BPJS Ketenagakerjaan (Mubarrak, 2016).

BPJS kesehatan adalah sebuah lembaga asuransi kesehatan berbadan hukum, yang menjalankan program berdasarkan UU nomor 24 tahun 2011. Yang mana dengan dibentuknya BPJS kesehatan maka hal ini merupakan sebuah bentuk perlindungan sosial yang diberikan pemerintah kepada masyarakat Indonesia untuk menjamin agar dapat memenuhi seluruh kebutuhan dasar hidup rakyat Indonesia yang lebih baik dan lebih layak. Dimana dasar asas yang di gunakan oleh BPJS dalam menyelenggarakan sistem jaminan kesehatan nasional merupakan sistem yang berpedoman pada asas kemanusiaan, dengan manfaat keadilan sosial bagi seluruh rakyat Indonesia (Itang, 2015).

Keanggota atau peserta BPJS Kesehatan adalah setiap warga negara Indonesia, maupun warga negara asing yang menetap atau bekerja di Indonesia paling sebentar 6 (enam) bulan, dan telah membayar iuran, yang meliputi: pertama, Orang yang tidak mampu dan fakir miskin, dengan penetapan peserta sesuai ketentuan peraturan perundang-undangan. Merupakan salah satu
Kajian Ekonomi Syariah Dalam Pelaksanaan....

bentuk dari Penerima Bantuan Iuran (PBI) jaminan kesehatan. Kedua, Yang bukan merupakan Penerima Bantuan Iuran (Non PBI) Jaminan Kesehatan yang meliputi, Pegawai Negri Sipil (PNS), Pejabat Negara, Anggota TNI, Anggota Polri, Pegawai Swasta, Pegawai Pemerintah Non PNS dan termasuk orang asing yang menetap paling sedikit enam bulan.

Peserta BPJS Kesehatan yang di tanggung, yang merupakan anggota keluarga, Pekerja penerima upah yang terdiri dari keluarga inti yang meliputi suami atau isteri dan anak kandung, anak angkat yang tercantum dalam KK (Ade, 2019).

Prosedur yang harus diperhatikan oleh masyrakat Indonesia dalam melakukan pendaftaran sebagai calon anggota peserta BPJS Kesehatan, di antaranya adalah sebagai berikut (Lisnawati, 2019):

Penerima Bantuan Iuran / PBI Pendaftaran bagi penerima bantuan (PBI) seperti fakir miskin dan orang tidak mampu, dilakukan oleh badan pusat statistik (BPS) sebagai penyelenggara urusan Pemerintahan di bidang statistik, dengan melakukan surpei lapangan dan diverifikasi oleh Kementerian Sosial.

Pemerintah daerah berdasarkan SK Gubernur, Bupati, Walikota atau bagi Pemda yang mengintegrasikan program Jamkesda ke program JKN, juga dapat mendaftarkan penduduk atau masyarakatnya sebagai peserta PBI yang ditetapkan oleh Pemerintah Pusat.

Pekerja Penerima Upah / PPU.

Pendafataran bagi peserta penerima upah (PPU) dilakukan Perusahaan atau badan usaha tempat dimana peserta bekerja, dimana perusahaan atau badan usaha wajib mendaftarkan seluruh karyawan dan anggota keluarganya ke Kantor BPJS Kesehatan yang ada di daerah tersebut, dengan melampirkan: Data anggota keluarga, Formulir Registrasi Badan Hukum yang di miliki perusahaan.

Kantor BPJS Kesehatan menerima bukti pembayaran iuran yang kemudian di buatkan

EKSISBANK (Ekonomi Syariah dan Bisnis Perbankan), Volume 4, Nomor 2, Desember 2020 


\section{Kiki Erika}

kartu ID dan mencetak kartu JKN secara mandiri oleh Perusahaan atau Badan Usaha. Nomor akun diberikan kepada perusahaan atau badan uaha untuk dilakukan pembayaran ke Bank yang ditunjuk atau yang telah bekerja sama dengan BPJS Kesehatan (BRI/Mandiri/BNI).

Pendaftaran Peserta Bukan Penerima Upah PBPU dan Bukan Pekerja.

Calon peserta mendaftarkan diri secara perorangan, Calon peserta juga mendaftarkan seluruh anggota keluarga yang ada di Kartu Keluarga, Calon Peserta wajib mengisi formulir Daftar Isian Peserta (DIP) dengan melampirkan: Fotokopi KTP/Paspor, masingmasing 1 lembar, Fotokopi Kartu Keluarga (KK), Pasfoto 3 x 4, masing-masing sebanyak 1 lembar, Fotokopi Buku Tabungan salah satu peserta yang ada dalam Kartu Keluarga, Nomor akun diperoleh calon peserta Setelah proses pendaftaran selesai, Peserta dapat melakukan pembayaran iuran ke Bank yang bekerja sama dengan BPJS Kesehatan (BRI/Mandiri/BNI).

BPJS Kesehatan wajib menerima bukti pembayaran dari peserta sebagia bukti untuk kemudian dicetakkan kartu JKN. Pelayanan kesehatan tingkat pertama yang di tanggung leh BPJS Kesehatan mencangkup (Irma, 2017) (Ade, 2019): Administrasi pelayanan, Pemeriksaan, pengobatan dan konsultasi, Pelayanan obat, alat kesehatan dan bahan medis habis pakai, Rehabilitasi medis, Pelayanan darah, Perawatan inap, Pemeriksaan penunjang diagnostik laboratorium, Pelayanan keluarga berencana, Pemulasaraan jenazah.

Pelaksaannya terkait penyakit dan kondisi medis yang sering menyerang masyarakat dan dapat ditanggung oleh BPJS yaitu: Penyakit jantung Asthma, Stroke, Kondisi medis dari kecelakaan lalu lintas, Kanker, Diabetes type 1 \& 2, dan Tuberculosis paru. Sedangkan untuk biaya operasi yang ditanggung BPJS yaitu: Operasi jantung, operasi caesar, operasi kista, operasi miom, operasi tumor, operasi odontektomi, operasi
Kajian Ekonomi Syariah Dalam Pelaksanaan....

bedah mulut, operasi usus buntu operasi batu empedu, operasi mata, operasi bedah vaskuler, operasi amandel, operasi katarak, operasi hernia, operasi kanker, operasi kelenjar getah bening, operasi pencabutan pen, operasi penggantian sendi lutut, dan operasi tubektomi (Lisnawati, 2019).

Berikut adalah klaim Rawat Jalan Tingkat Pertama dari BPJS Kesehatan ke Puskesmas:

Table 1

Klaim Rawat Jalan Tingkat Pertama

\begin{tabular}{|l|l|l|}
\hline NO & \multicolumn{1}{|c|}{$\begin{array}{c}\text { FASILITAS } \\
\text { KESEHATAN }\end{array}$} & \multicolumn{1}{c|}{ TARIF } \\
\hline 1 & $\begin{array}{l}\text { Puskesmas atau } \\
\text { fasilitas kesehatan } \\
\text { yang setara }\end{array}$ & $\begin{array}{l}\text { Rp. 3.000,00 s.d } \\
\text { Rp 6.000,00 }\end{array}$ \\
\hline 2 & $\begin{array}{l}\text { RS Pratama, Klinik } \\
\text { Pratama, Praktek } \\
\text { Dokter atau Fasilitas } \\
\text { Kesehatan yang setara }\end{array}$ & $\begin{array}{l}\text { Rp. 8.000,00 s.d } \\
\text { Rp 10.000,00 }\end{array}$ \\
\hline 3 & $\begin{array}{l}\text { Praktik Dokter Gigi di } \\
\text { luar Fasilitas } \\
\text { Kesehatan no 1 atau 2 }\end{array}$ & Rp. 2.000.00 \\
\hline
\end{tabular}

Sumber: Panduan Praktis administrasi klaim faskes BPJS Kesehatan.

Dampaknya yang dirasakan langsung oleh kami selaku masyarakat, selama ini kami merasa terbantu dengan adanya BPJS Kesehatan, apalagi bagi masyarakat yang Penerima Bantuan Iuran (PBI) seperti saya, itu sangat membantu sekali karena keseluruhan pembayarannya ditanggung oleh pemerintah. Dalam pembayaran individu yang tidak di tanggung oleh pemerintah iuaran di BPJS Kesehatan juga sangat murah terjangkau oleh masyarakat kecil menengah. Sedangkan untuk pelayanan BPJS Kesehatan di puskesmas palasari lumayan baik karena pasien tidak perlu medical check up sehingga pasien tidak perlu mengeluarkan biaya tambahan (Nana et al., 2019).

Namun dalam pelayanannya BPJS Kesehatan juga memiliki beberapa kekurangan dan sering kali para peserta mengeluh, seperti yang dikatakan oleh Ibu Jasmin dan Ibu Cahyati. BPJS Kesehatan tidak bisa langsung ke Rumah Sakit, peserta

EKSISBANK (Ekonomi Syariah dan Bisnis Perbankan), Volume 4, Nomor 2, Desember 2020 


\section{Kiki Erika}

diharuskan memeriksakan penyakitnya ke faskes 1 terlebih dahulu, setelah ke faskes 1 (Puskesmas) dan pasien memang dirasa harus ke rumah sakit, maka pasien atau peserta BPJS Kesehatan baru bisa ke rumah sakit. Terkadang jenis obat yang disediakan juga terbatas hanya obat-obat tertentu saja yang tersedia di peskesmas (Jasmin, 2019). Pasien atau Peserta BPJS Kesehatan juga harus lama antri ketika sedang menyelesaikan pembayaran dengan kartu BPJS, tidak hanya itu Pasien juga harus menunggu untuk mendapat giliran kamar (Cahyanti, 2019).

\section{B. Kajian Ekonomi Syariah Dalam}

\section{Pelaksanaan Asuransi Jaminan}

Kesehatan di Faskes Pertama Layanan

BPJS Puskesmas Palasari Kabupaten

\section{Subang}

Ulama adalah pewaris dari Nabi, karena itu keberadaan seorang ulama saat ini sangat dibutuhka oleh umat manusia sebagai seorang tokoh agama yang dapat memberikan pandangan hukum terhadap masalah-masalah kontemporer, yang mana masalah tersebut tidak terdapat pada jaman Rasulullah SAW. Sehingga pandangan yang diberikan oleh seorang ulama diharapkan dapat memberikan kejelasan sebuah hukum dan mengurangi biyas persepsi terhadap suatu permasalahan hukum yang terjadi ditengah masyarakat. Karena ulama merupakan seseorang yang dianggap memiliki kelebihan ilmu dalam bidang gama Islam, sehingga dengan ilmu yang dimilikinya seorang ulama dapat memberikan pandanganya terhadap masalahmasalah kontemporer yang banyak terjadi pada saat ini.

Menurut Musthafa Ahmad Az-Zarqa memaknai asuransi sebagai suatu cara atau metode untuk memelihara manusia dalam menghindari risiko (ancaman) bahaya yang beragam yang akan terjadi dalam hidupnya, dalam perjalanan kegiatan hidupnya atau dalam aktivitas ekonominya. Ia berpendapat bahwa sistem asuransi adalah sistem ta'awun dan tadhamun yang bertujuan untuk
Kajian Ekonomi Syariah Dalam Pelaksanaan....

menutupi kerugian peristiwa-peristiwa atau musibah-musibah oleh sekelompok tertanggung kepada orang yang tertimpa musibah tersebut. Penggantian tersebut berasal dari premi mereka (Sula, 2004a). Sedangkan Menurut Pak H. Dadan Hamdani (wakil ketua MUI Kabupaten Subang) beliau berpendapat tentang BPJS Kesehatan yaitu sebagai berikut:

Pertama, pandangannya terhadap Asuransi BPJS kesehatan Majlis Ulama Indonesia Kabupaten Subang memberi pernyataan bahwa BPJS Kesehatan merupakan asuransi yang dibentuk langsung oleh Pemerintah atau Negara. Adapun transaksi yang digunakan dalam asuransi BPJS Kesehatan adalah transaksi yang sesuai dengan syariat Islam, dimana didalamnya terdapat unsur ta'awun (tolong menolong) yang berupa jaminan gotong royong. Dimana setiap orang diwajibkan untuk membayarkan sejumlah uang yang besarnya sudah ditentukan berdasarkan kelasnya masing-masing. Kemudian uang yang terkumpul dipersilahkan untuk digunakan kepada siapapun yang membutuhkannya.

Kedua, Menyikapi program asuransi BPJS Kesehatan yang telah dijalankan oleh pemerintah, Majlis Ulama Indnesia Subang yang di wakilkan oleh Pak Hamdan dalam hal ini memperbolehkan apa yang telah dilakukan pemerintah tapi denga catatancatatan harus diperbaiki mekanisme baik dari segi SDM, teknis dan lain sebagainya yang masih menyebabkan timbulnya permasalahan-permasalahan di dalam menjalankan program tersebut. Seperti pemerintah harus benar-benar mempersiapan SDM yang sangat memadai supaya dapat mengurangi dan meminimalisir kesalahankesalahan yang terjadi dilapangan dalam menjalankan program asuransai BPJS kesehatan. Selain memperbaiki dalam segi mekanisme, teknis, dan sdm, Pemerintah juga harus memberikan pemahaman kepada seluruh rumah sakit untuk bisa bekerja sama 


\section{Kiki Erika}

demi meningkatkan kualitas layanan dan mutu yang lebih baik.

Berikut adalah tabel Penyesuaian antara teori asuransi syariah dengan praktek pelaksanaan BPJS Kesehatan di Puskesmas Palasari Ciater Subang

\section{Tabel 4.2}

Ketentuan terkait luran dan Layanan

Dalam Fatwa No. 98/DSN-MUI/XII/2015

Tentang Pedoman Penyelenggaraan Jaminan Sosial Kesehatan Syariah

\begin{tabular}{|c|c|c|c|}
\hline \multirow{2}{*}{$\begin{array}{l}\mathbf{N} \\
\mathbf{O}\end{array}$} & \multirow{2}{*}{ Uraian } & \multicolumn{2}{|c|}{$\begin{array}{c}\text { Kesesuaian } \\
\text { Syariah }\end{array}$} \\
\hline & & Ya & Tidak \\
\hline 1 & $\begin{array}{l}\text { BPJS Kesehatan harus memberikan } \\
\text { kemudahan bagi semua peserta BPJS } \\
\text { di seluruh wilayah Indonesia untuk } \\
\text { mendapatkan pelayanan yang baik } \\
\text { sesuai dengan hak mereka; }\end{array}$ & & $\sqrt{ }$ \\
\hline 2 & $\begin{array}{l}\text { BPJS Kesehatan sebagai wakil } \\
\text { Peserta-Kolektif wajib memberikan } \\
\text { informasi yang jelas kepada Peserta } \\
\text { Individu terkait jumlah iuran dan } \\
\text { manfaat atau cakupan layanan fasilitas } \\
\text { kesehatan yang ditanggung Genis } \\
\text { layanan, tingkat layanan, tenaga } \\
\text { medis, penunjang diagnostik, obat, } \\
\text { bentuk-bentuk terapi, dan biaya-biaya } \\
\text { layanan kesehatan lainnya); }\end{array}$ & & $\sqrt{ }$ \\
\hline 3 & $\begin{array}{l}\text { BPJS Kesehatan sebagai wakil } \\
\text { Peserta-Kolektif wajib bertanggung- } \\
\text { jawab untuk mengupayakan agar } \\
\text { besaran pembayaran imbalan dan } \\
\text { membayarnya kepada fasilitas layanan } \\
\text { kesehatan (Faskes) melalui sistem } \\
\text { yang adil dan transparan; }\end{array}$ & & $\sqrt{ }$ \\
\hline 4 & $\begin{array}{l}\text { BPJS Kesehatan wajib menunaikan } \\
\text { kewajibannya dengan baik kepada } \\
\text { Faskes sesuai perjanjian; }\end{array}$ & & $\sqrt{ }$ \\
\hline 5 & $\begin{array}{l}\text { Faskes wajib memberikan layanan } \\
\text { kesehatan kepada Peserta Individu } \\
\text { sesuai prinsip-prinsip syariah serta } \\
\text { peraturan perundang-undangan yang } \\
\text { berlaku; wajib menolong pasien dan } \\
\text { dilarang menolak dan/atau mengabai- } \\
\text { kannya; }\end{array}$ & & $\sqrt{ }$ \\
\hline 6 & $\begin{array}{l}\text { Faskes/Rumah Sakit wajib memberi- } \\
\text { kan imbal jasa yang berasal dari BPJS } \\
\text { Kesehatan kepada para dokter dan } \\
\text { paramedik serta semua unsur di dalam } \\
\text { Faskes sesuai dengan prinsip keadilan } \\
\text { dan prinsip-prinsip syariah serta }\end{array}$ & $\sqrt{ }$ & \\
\hline
\end{tabular}

Kajian Ekonomi Syariah Dalam Pelaksanaan....

peraturan perundang-undangan yang

berlaku.

Berdasarkan Tabel 4.2 diatas dapat dijelaskan terkait BPJS Kesehatan harus memberikan kemudahan bagi semua peserta BPJS di seluruh wilayah Indonesia untuk mendapatkan pelayanan yang baik sesuai dengan hak mereka, belum sesuai Syariah. Karena para peserta BPJS hanya mendapatkan layanan kesehatan di tempat yang tercantum pada faskes pertama, termasuk di faskes Puskesmas Palasari Ciater Subang hanya menerima yang faskes pertamanya di Puskesmas Palasari Ciater Subang. Perbedaan kelas juga mempengaruhi layanan kesehatan yang ada di Puskesmas Palasari Ciater Subang.

Selanjutnya point kedua tentang BPJS Kesehatan sebagai wakil Peserta-Kolektif wajib memberikan informasi yang jelas kepada Peserta Individu terkait jumlah iuran dan manfaat atau cakupan layanan fasilitas kesehatan yang ditanggung (Jenis layanan, tingkat layanan, tenaga medis, penunjang diagnostik, obat, bentuk-bentuk terapi, dan biaya-biaya layanan kesehatan lainnya); belum sesuai Syariah. Karena BPJS Kesehatan tidak menjelaskan secara detail mengenai informasi yang jelas kepada Peserta Individu terkait jumlah iuran dan manfaat atau cakupan layanan fasilitas kesehatan yang ditanggung. Dan menurut peneliti terjadi ketidak jelasan pada saat peserta bayar premi bulanan, namun tidak jelas berapa jumlah yang akan diterima. Bisa lebih besar, bisa kurang. Di situlah unsur gharâr (ketidak jelasan) dan untung-untungan. Ketika gharâr itu sangat kecil, mungkin tidak menjadi masalah. Karena hampir dalam setiap jual beli, ada unsur gharâr, meskipun sangat kecil. Dalam asuransi kesehatan BPJS, tingkatannya nasional. Artinya, perputaran uang di sana sangat besar. Bisa bayangkan ketika sebagian besar WNI menjadi peserta BPJS, dana ini bisa mencapai angka triliyun. Jika dibandingkan untuk biaya pemeliharaan kesehatan warga, akan sangat jauh selisihnya, disana terdapat unsur gharâr-nya sangat besar. Dari Abû Hurayrah Ra, mengatakan: "Rasulullah Saw .melarang jual beli gharâr." (HR. Muslim 1513). Di Puskesmas Palasari Ciater Subang pun terdapat ketidak jelasan dalam memberikan layanan kepada pasien BPJS

EKSISBANK (Ekonomi Syariah dan Bisnis Perbankan), Volume 4, Nomor 2, Desember 2020 


\section{Kiki Erika}

Kesehatan padalah mereka bayar premi setiap bulannya.

Selanjutnya Point 3 terkait BPJS Kesehatan sebagai wakil Peserta-Kolektif wajib bertanggungjawab untuk mengupayakan agar besaran pembayaran imbalan dan membayarnya kepada fasilitas layanan kesehatan (Faskes) melalui sistem yang adil dan transparan; belum sesuai dengan Syariah, karena di Puskesmas Palasari Ciater Subang masih banyak pembayaran dari Pihak BPJS Kesehatan yang menurut peneliti belum adil dan transparan, serta masih ditemukannya tunggakan seperti di Kota-kota besar.

Selanjutnya point 4 terkait BPJS Kesehatan wajib menunaikan kewajibannya dengan baik kepada Faskes sesuai perjanjian, masih belum sesuai juga dengan Syariah, karena pihak BPJS Kesehatan masih ditemukan ketidak tepatan dalam menunaikan kewajibannya kepada faskes Pertama termasuk di Puskesmas Palasari Ciater Subang.

Selanjutnya Point 5 tentang Faskes wajib memberikan layanan kesehatan kepada Peserta Individu sesuai prinsip-prinsip syariah serta peraturan perundang-undangan yang berlaku; wajib menolong pasien dan dilarang menolak dan/atau mengabaikannya, hal ini masih belum sesuai Syariah. Karena Pihak Puskesmas Palasari Subang masih membeda-bedakan dan masih mengkelas-kelaskan layanan kesehatan, hal ini yang menurut peneliti masih belum ada prinsip keadilan dan murni prinsip ta'awun.

Selanjutnya point ke 5 tentang Faskes/ Rumah Sakit wajib memberikan imbal jasa yang berasal dari BPJS Kesehatan kepada para dokter dan paramedik serta semua unsur di dalam Faskes sesuai dengan prinsip keadilan dan prinsipprinsip syariah serta peraturan perundangundangan yang berlaku, Sudah sesuai dengan Syariah. Karena Pihak Puskesmas Palsari Subang mendapat Biaya perawatan dan paramedic dari pihak BPKS Kesehatan, walaupun kadang terjadi keterlambatan pembayaran.

\section{KESIMPULAN}

Berdasarkan hasil penelitian dan pembahasan yang telah diuraikan, maka dapat diambil kesimpulan sebagai berikut:
Kajian Ekonomi Syariah Dalam Pelaksanaan....

BPJS merupakan jaminan asuransi dari pemerintah untuk seluruh masyarakat indonesia namun masih sebagian masyarakat yang terdaftar sebagai nasabah BPJS kesehatan. BPJS berusaha untuk memudahkan peserta dalam melakukan pembayaran, tujuannya agar dana dapat terhimpun sesuai yang diharapakan. Pelaksanaan BPJS Kesehatan di Puskesmas Palasari Subang melayani sudah dengan sebaik mungkin kepada seluruh peserta BPJS Kesehatan,dari mulai mereka datang ke Puskesmas Palsari Subang membawa kartu lalu di klik di tiketnya dan mereka merupakan anggota aktif. Walaupun masih ada ditemukan layanan-layanan BPJS Kesehatan di Puskesmas Palsari Subang yang belum memuaskan.

Perspsektif Ekonomi Syariah Dalam Pelaksanaan Asuransi Jaminan Kesehatan di Faskes Pertama Layanan BPJS Puskesmas Palasari Kabupaten Subang masih banyak ditemukan belum sesuai dengan Syariah, dari mulai kemudahan peserta dalam mendapatkan layanan Kesehatan, informasi terkait manfaat atas iuran peserta yang di bayarkan, pembayaran pihak BPJS terhadap Puskesmas Palasari Subang, hingga layanan Faskes pertama Puskesmas Palsari Subang yang mengandung prinsip ketidak adilan dan ketidak murnian prinsip ta'awun. Hal ini terjadi karena keterbatasan pengetahuna pihak pengelola BPJS Kesehatan di Puskesmas Palasari Subang terhadap Syariah. Jika melihat jasa pihak BPJS Kesehatan kepada para dokter dan paramedik menurut peneliti sudah sesuai Syariah, walaupun masih ditemukan keterlambatan bayar dari pihak BPJS Kesehatan kepada Puskesmas Palasari Subang.

DAFTAR PUSTAKA

Ade. (2019). Wawancara Tentang Pelaksanaan Asuransi Jaminan Kesehatan Pada Faskes Pertama Layanan BPJS Puskesmas Palasari Subang. (Selaku Peserta BPJS

EKSISBANK (Ekonomi Syariah dan Bisnis Perbankan), Volume 4, Nomor 2, Desember 2020 
Kiki Erika

Kesehatan Kab. Subang).

Ali, H. (2004). Asuransi dalam Perspektif Hukum Islam. Kencana.

Ananta, I. (2017). Sistem Kapitasi BPJS Kesehatan Dalam Tinjauan Syariah. Konferensi Nasional Ilmu Sosial Dan Teknologi, 1(1). http://seminar.bsi.ac.id/knist/index.php/ UnivBSI/article/view/116/112

Arikunto, S. (2002). Prosedur Penelitian. PT. Rineka Cipta.

Cahyanti. (2019). Wawancara Tentang Pelaksanaan Asuransi Jaminan

Kesehatan Pada Faskes Pertama Layanan BPJS Puskesmas Palasari Subang. (Selaku Peserta BPJS Kesehatan Kab. Subang).

Capra, U. (1997). Al-Qur'an Menuju Sistem Moneter yang Adil. PT Dana Bakti Prima Yasa.

Dahlan, A. A. (2000). Enksiklopedi Hukum Islam (4th ed.). Ichtiar Baru Van Hoeve.

Dewi, G. (2004). Aspek-Aspek Hukum Dalam Perbankan dan Perasuransian Syariah Di Indonesia. Kencana.

Dewi, R. K., Nuryadi, N., \& Sandra, C. (2016). Identifikasi Pelayanan Promotif pada Fasilitas Kesehatan Tingkat Pertama Program Jaminan Kesehatan Nasional. Pustaka Kesehatan2, 4(2). http://jurnal.unej.ac.id/index.php/JPK/art icle/view/3235

Ganie, J. (2013). Hukum Asuransi di Indonesia. Sinar Grafika.

Irma, A. (2017). Peran Instagram Sebagai Media Komunikasi Pemasaran Bisnis Online (Studi Deskriptif Kualitatif Pada Bisnis Online Beautyhomeshop). Jurnal Online Kinestik, 4(2), 1-12.

Itang, I. (2015). BPJS Kesehatan dalam Perspektif Ekonomi Syariah. AHKAM : Jurnal Ilmu Syariah, 15(2).
Kajian Ekonomi Syariah Dalam Pelaksanaan....

https://doi.org/10.15408/ajis.v15i2.2859

Jasmin. (2019). Wawancara Tentang Pelaksanaan Asuransi Jaminan

Kesehatan Pada Faskes Pertama Layanan BPJS Puskesmas Palasari Subang. (Selaku Peserta BPJS Kesehatan Kab. Subang).

Lisnawati. (2019). Wawancara Tentang Pelaksanaan Asuransi Jaminan

Kesehatan Pada Faskes Pertama Layanan BPJS Puskesmas Palasari Subang. (Selaku Pegawai BPJS Kesehatan Kabupaten Subang).

Listiyana, I., \& Rustiana, E. R. (2017). Analisis Kepuasan Jaminan Kesehatan Nasional Pada Pengguna BPJS Kesehatan Di Kota Semarang. Unnes Journal of Public Health, 6(1), 53. https://doi.org/10.15294/ujph.v6i1.1161 5

Majid, J., \& Saputra, R. E. (2020). Social Accounting; Tendensi Kemaslahatan Publik dibalik Kenaikan Tarif BPJS Kesehatan di Indonesia. Jurnal Sosial Ekonomi Dan Humaniora, 6(1), 44-53. https://doi.org/10.29303/jseh.v6i1.74

Mubarrak, H. (2016). Kontroversi Asuransi di Indonesia: Telaah Fatwa Majelis Ulama Indonesia (MUI) tentang Badan Penyelenggara Jaminan Sosial (BPJS). TSAQAFAH, 12(1), 105. https://doi.org/10.21111/tsaqafah.v12i1. 370

Nana, Dewi, \& Surya. (2019). Wawancara Tentang Pelaksanaan Asuransi Jaminan Kesehatan Pada Faskes Pertama Layanan BPJS Puskesmas Palasari Subang. (Selaku Peserta BPJS Kesehatan Kab. Subang).

Nurmatias, F., Sulistyandari, S., \& Dina, M. (2017). Perspektif Hukum Islam Terhadap Iuran BPJS Kesehatan. In IQTISHADUNA: Jurnal Ilmiah Ekonomi Kita (Vol. 6, Issue 2).

EKSISBANK (Ekonomi Syariah dan Bisnis Perbankan), Volume 4, Nomor 2, Desember 2020 
Kiki Erika

http://ejournal.stiesyariahbengkalis.ac.id /index.php/iqtishaduna/article/view/108

Putrawan, G., Junaid, J., \& Ismail, C. S. (2016). Studi Kualitatif Pelaksanaan Jaminan Kesehatan Nasional Oleh BPJS Kesehatan Di Kecamatan Tinanggea Kabupaten Konawe Selatan. In JIM KESMAS (Jurnal Ilmiah Mahasiswa Kesehatan Masyarakat) (Vol. 1, Issue 3). https://doi.org/10.37887/JIMKESMAS. V1I3.1244

RI, D. A. (2009). Al-Qur'an dan Terjemahnya. PT. Sygma Examedia Arkanlemma.

Setiawati, M. E., \& Nurrizka, R. H. (2019). Evaluasi Pelaksanaan Sistem Rujukan Berjenjang Dalam Program Jaminan Kesehatan Nasional. JKKI; Jurnal Kebijakan Kesehatan Indonesia, 8(1), 113. https://doi.org/10.22146/jkki.43843

Sipahutar, E. S. (2020). Analisis Hukum Pelaksanaan dan Pelayanan Bagi Pengguna Jaminan Kesehatan Menurut UU No. 24 Tahun 2011 Tentang Badan Penyelenggara Jaminan Sosial. Doktrina: Journal Of Law, 3(1), 87-97. https://doi.org/10.31289/doktrina.v3i1.3 528

Suharto, E. (2009). Kemiskinan dan perlindungan sosial di Indonesia: menggagas model jaminan sosial universal bidang kesehatan: dilengkapi dengan: UU No. 40/2004 tentang sistem jaminan sosial nasional, UU No. 11/2009 tentang kesejahteraan sosial. Alfabeta.

Sukardi, D. (2016). Pengelolaan Dana Badan Penyelenggara Jaminan Sosial (BPJS) Kesehatan Dalam Perspektif Hukum Islam. Mahkamah: Jurnal Kajian Hukum Islam, 1(1), 96-104.

Sula, M. S. (2004a). Asuransi Syariah (Life and General): Konsep dan Sistem Operasional (Cetakan Ke). Gema Insani
Kajian Ekonomi Syariah Dalam Pelaksanaan.... Press.

Sula, M. S. (2004b). Asuransi Syariah (life and General) Konsep dan sistem Operasional. Gema Insani.

Suryani, A. I., \& Suharyanto, A. (2016). Implementasi Program Badan Penyelenggara Jaminan Kesehatan (BPJS) Dalam Meningkatkan Pelayanan Administrasi Kesehatan di Rumah Sakit Umum Sibuhuan. Publikauma: Jurnal Administrasi Publik Universitas Medan Area, 4(1), 86-99. https://doi.org/10.31289/PUBLIKA.V4I 1.889

EKSISBANK (Ekonomi Syariah dan Bisnis Perbankan), Volume 4, Nomor 2, Desember 2020 